\title{
ACAMPAMENTO E ASSENTAMENTO: PARTICIPAÇÃO, EXPERIÊNCIA E VIVÊNCIA EM DOIS MOMENTOS DA LUTA PELA TERRA
} CAMPAMIENTO E ASENTAMIENTO: PARTICIPACION, EXPERIENCIA Y VIVENCIA EN DOS MOMENTOS DE LA LUCHA POR LA TIERRA OCCUPANCY AND SETTLEMENT: PARTICIPATION, EXPERIENCE, AND GRASPS OF LIFE EXPERIENCE (ERFAHRUNG)

\author{
Gislayne Cristina Figueiredo \\ Universidade Paulista, São Paulo/SP, Brasil \\ José Marcelino de Rezende Pinto \\ Universidade de São Paulo, São Paulo/SP, Brasil
}

\begin{abstract}
RESUMO
Neste trabalho, objetivamos discutir a participação de indivíduos assentados em um movimento de luta pela reforma agrária (o MST), em dois momentos diferentes: o acampamento e o assentamento. A partir dos subsídios dados pela psicologia social de Adorno, e analisando um caso concreto, podemos refletir que a participação no MST representa uma possibilidade de que os indivíduos tenham, na época do acampamento, uma experiência (Erfahrung), que se coloquem de maneira reflexiva frente ao mundo administrado, tendo uma possibilidade de desenvolvimento do pensamento não tutelado e criando um conteúdo coletivo e um significado partilhado para suas ações. Por outro lado, com a entrada da lógica da mercadoria e do princípio do equivalente no assentamento, a vivência (Erlebnis) tende a tomar o lugar da experiência, e os indivíduos tendem a voltar a se adaptar ao mundo administrado, o que causa uma série de rompimentos e desencontros.
\end{abstract}

Palavras- chave: movimentos sociais; experiência; Escola de Frankfurt; T.W. Adorno.

\section{RESUMEN}

En este trabajo, nos proponemos analizar y discutir la participación de individuos asentados en un movimiento de lucha por la reforma agraria (el MST- Movimiento de los Sin Tierra), en dos momentos diferentes: el campamiento y el asentamiento. A partir de las subvenciones otorgadas por la psicología social de Adorno y el análisis de un caso concreto, podemos reflexionar que la participación en MST es la posibilidad de que las personas tengan, en el momento del campamento, una experiencia (Erfahrung), que se coloquen de manera reflexiva frente al mundo administrado, con una posibilidad de desarrollo de pensamiento no tutelados y la creación de un contenido colectivo y un sentido compartido de sus actos. Por otro lado, con el adviento de la lógica de la mercancía y del principio del equivalente no asentamiento, la vivencia (Erlebnis) tiende a tomar el lugar de la experiencia y los individuos tienden a volver a adaptarse al mundo administrado, lo que causa una serie de interrupciones y fallos.

Palabras clave: movimientos sociales; experiencia; Escuela de Frankfurt; T.W. Adorno.

\begin{abstract}
This research aims to discuss the participation of settled individuals in a movement struggling for land reform (MST- Movement of the Landless) at two different moments: occupancy and settlement. Starting from the social psychology of Adorno, and analising a particular case, we may reflect that the participation in the MST represented a possibility, that the individuals had at the time of the occupancy - an experience (Erfahrung). They placed themselves in a reflective manner regarding the administered world, they had the possibility of developing their own train of thought, e.i. without being tutored. On the other hand, with the logics of merchandise and the principle of equivalence in the settlement, an actual experience (Erlebnis) tends to overtake the experience, and the individuals tend to once again adapt themselves to the known administered world. This fact causes a series of break off relations and disagreements or conflicts.
\end{abstract}

Keywords: social moviments; experience (Erfahrung); Frankfurt school; T.W. Adorno. 


\section{Acampamento e assentamento: momentos diferentes da luta}

Os acampamentos de trabalhadores rurais têm sido um importante instrumento de luta pela conquista da terra. Eles fazem parte da estratégia de luta, que, para alguns teóricos, é o que diferencia o MST de outros movimentos sociais do campo (Medeiros, 2003). De acordo com Caldart (2004), os acampamentos podem ser considerados como cidades "de barracos de lona" (p. 176), em uma referência ao material e ao tipo de habitação que são utilizados nessa manifestação social. Ainda segundo a mesma autora, os acampamentos podem ser construídos na área que se pretende transformar em assentamento, ou à margem de rodovias, do lado de fora das fazendas, etc... Cada um deles demanda estratégias de sobrevivência diferentes, mas todos visam explicitar a luta, pressionar governos e mobilizar a opinião pública sobre a questão da terra.

Os acampamentos são organizados sob a lógica da participação e da reflexão, através de instâncias coletivas de decisão, como as assembleias, e de instâncias participativas de gestão e de trabalho, chamadas de Coletivos, que se ocupam dos mais diversos assuntos e ações necessários ao funcionamento e manutenção daquele grupo, como saúde, educação, mobilização, segurança, etc. Conforme Stédile (1997, p. 104), "todas as instâncias do Movimento ${ }^{1}$, desde as comissões de base, dentro de um acampamento, até as instâncias nacionais, são exercidas coletivamente, na forma de colegiado, sem distinção de poder".

Para aqueles pesquisadores que estudam especificamente o período de acampamento, este se caracteriza como um momento de transição ou de passagem, durante o qual o acampado rompe com sua identidade/papel anterior, mas ainda não alcança o novo lugar pretendido (o de assentado), lugar este que permitiria um enraizamento definitivo (Turatti, 2005). Nas palavras da autora, o acampamento pode ser considerado um "momento intersticial" (p. 70).

Assim, o acampamento é um momento de ruptura na vida dos indivíduos que dele participam, pois indica não somente o ingresso em uma luta, mas o rompimento com uma posição passiva frente à situação de pauperização e marginalização vivida pelo indivíduo (Caldart, 2004). A ruptura também faz referência à experimentação de uma nova situação de vida, com a possibilidade de aprendizagem de uma forma de convivência mais coletiva e comunitária.

O acampamento é entendido pelo movimento social como um espaço privilegiado de formação dos futuros assentados (Caldart, 2004). Tal ênfase na formação, durante o acampamento, se justifica por ser este um momento no qual os participantes podem se constituir "como um novo sujeito social, no sentido de sujeito coletivo que passa a participar dos embates sociais" (Caldart, 2004, p. 34). Ao participarem da luta pela terra, os sujeitos reorganizariam sua identidade social a partir dessa experiência singular, posto que a ocupação de terra e a vida no acampamento proporcionam uma experiência que questiona os padrões culturais prévios dos acampados, levando a uma "mudança de conceitos, de valores, de postura diante de determinadas realidades" (Caldart, 2004, p. 35).

Os Sem Terra, como sujeitos sociais e culturais, seriam diferenciados dos participantes de outros movimentos sociais por aquilo que a autora vai denominar de "enraizamento projetivo": a experiência de participar no MST proporciona o enraizamento de uma população que antes era desenraizada, ao mesmo tempo que fornece um projeto de futuro, de "algo que ainda não é, mas pode vir a ser" (Caldart, 2004, p. 35). Nesse sentido, vários teóricos têm pontuado que a participação no movimento social de luta pela terra, para além do assentamento, contribui com a construção de uma identidade coletiva e com a reconstrução da subjetividade individual (Caume, 2002; Schreiner, 2002).

Há que se pontuar, porém, que o acampamento também é um momento no qual se experiencia uma série de dificuldades, dificuldades essas que colocam em risco a própria existência física do acampado - fome, fragilidade dos barracos e exposição a intempéries, risco de violência de jagunços ou das forças policiais, despejos e remontagens constantes de barracos, entre outros (Caldart, 2004 ;Turatti, 2005).

Já o assentamento de trabalhadores rurais tem sido a principal resposta do Estado à pressão exercida pelos movimentos sociais demandantes por reforma agrária, no caso do Brasil, constituindo-se assim como uma tentativa de intervenção e controle estatal sobre um conflito social (Caume, 2002; Medeiros, 2003).

Oassentamentoé considerado tanto por estudiosos da área quanto pelo próprio movimento social como um momento da luta diferenciado do acampamento, posto que o assentamento dos trabalhadores é um indicador de que a terra já foi 'conquistada', e começase a organizar uma nova comunidade (Caldart, 2004; Confederação Nacional das Cooperativas de Reforma Agrária do Brasil, 2004; Turatti, 2005).

Segundo tal visão, é dentro desse espaço que o novo sujeito coletivo, constituído na luta pela terra, no período do acampamento, vai se desenvolver na direção 
de uma consciência plena, sendo que o assentamento seria um vislumbre do novo mundo que se pretende construir (Associação Nacional de Cooperação Agrícola, 2002; CONCRAB, 2004). O assentamento seria assim um local de novas relações sociais, relações estas construídas sobre valores de igualdade, justiça social, sem discriminação e livre do autoritarismo e da opressão (ANCA, 2002; CONCRAB, 2004).

Se, por um lado, vários autores têm demonstrado o avanço nas relações sociais e na democratização da sociedade brasileira trazido pelo MST, por outro lado, alguns outros têm sinalizado para a presença de conflitos e dificuldades de relacionamento na nova comunidade, bem como para a reprodução de relações assimétricas dentro dos assentamentos de reforma agrária implantados em função de sua ação. A união e a participação igualitária percebida durante o acampamento seriam substituídas por uma fragmentação e uma desmobilização dos assentados.

Na concepção de Leite (1997), há uma certa romantização do assentamento, alimentada pela imagem que o próprio grupo procura passar de si mesmo, de um comunitarismo interno, que nega as tensões inerentes a todos os processos sociais. Se as tensões e os conflitos são fato, as explicações para o fenômeno são diferentes, ora reportando-os à ação do movimento social, ora à ação dos assentados, ora à ação de outros atores que passam a atuar no espaço do assentamento.

Alguns dos teóricos que estudam a ação do MST dentro dos assentamentos reportam a fragmentação e a reprodução de relações assimétricas a razões culturais, considerando tanto as características culturais dos participantes do Movimento quanto do próprio MST. Nessa direção, alguns autores vão analisar os conflitos e contradições encontrados em assentamentos da reforma agrária ou na relação com o movimento social como decorrentes da diferença entre os projetos de vida dos assentados e os projetos das lideranças do movimento social e de outras agências externas que interferem no assentamento, como a Igreja e o Estado (Caume, 2002; Medeiros, 2003; Miranda, 1998; Sigaud, 2005). Em alguns textos produzidos pelo Movimento ou por teóricos ligados a ele, a fragmentação e os desentendimentos entre assentados e liderança são reportados a um recuo na consciência dos assentados, de tal forma que estes não assimilariam satisfatoriamente as lições e as experiências aprendidas durante a ocupação e o tempo de acampamento (Caldart, 2004; CONCRAB, 2004).

Vasquez (2002), estudando as relações dentro de um assentamento, ressalta que as diferenças pessoais, inclusive de objetivos dentro do movimento de luta pela terra, existiam antes e durante todo o processo de luta social, mas eram diminuídas e apaziguadas por um discurso religioso genérico, maleável o suficiente para ser interpretado por cada um segundo seus objetivos particulares. Portanto, desde a fase de acampamento, existiam objetivos e motivações pessoais diversas, que ficavam diluídos em função do objetivo maior, que era a conquista da terra, mas que se explicitaram posteriormente.

D'Incao e Roy (1995), estudando uma associação de assentados ligados a um movimento social, constataram o mau funcionamento das instâncias coletivas e de discussão e tomada de decisão, e a presença de um autoritarismo baseado nos laços de dominação e servilismo. Os autores vão explicar as relações assimétricas dentro de movimentos sociais progressistas como um comportamento aprendido nas relações sociais prévias à entrada do indivíduo no Movimento e que tem tendência a se repetir. $\mathrm{Na}$ verdade, segundo os autores, há uma tensão entre o desejo de escapar da subserviência e os padrões internalizados de submissão (D'Incao \& Roy, 1995).

Ainda que já seja considerável a bibliografia que pontua a existência de dificuldades nas relações e interações construídas dentro dos assentamentos, como afirma Caume (2002), essas dificuldades são apenas constatadas, sem maiores explicações quanto às suas origens e seus mecanismos. Outrossim, a fragmentação pós-assentamento é vista como anomia, como algo negativo e incomum, um desvio da comunidade que o assentamento certamente seria se não fossem as dificuldades trazidas pelo individualismo/ autoritarismo.

No entanto, o que se pode observar é que tal fragmentação da união existente no acampamento, depois que o grupo se torna assentado, é muito mais comum do que querem enxergar parte dos estudiosos do Movimento. Dados do levantamento quantitativo feito por Spavorek (2003), que abrangeu todos os assentamentos no território brasileiro com mais de um ano de implantação, indicam que, à exceção da região Sul, a organização dos assentados em cooperativas é ínfima, apontando a dificuldade dos assentados em comporem coletivos.

Assim, o objetivo do presente artigo é lançar um olhar mais atento para o momento de transição do acampamento para o assentamento, enfocando a diferença entre esses dois momentos da luta pela terra, e o impacto dessa mudança na participação do indivíduo nos coletivos e na organização da comunidade/grupo que estava mobilizado. 
Para realizar a análise de uma situação concreta, utilizamos as ferramentas dadas pela psicologia social de T.W. Adorno, mais precisamente os conceitos de experiência (Erfahrung) e vivência (Erlebnis).

\section{Vivência e experiência como categorias explicativas}

O conceito adorniano de experiência, inspirado em Walter Benjamin, faz referência a uma situação em que a história e o conteúdo individual se articulam com a história e o conteúdo coletivo, sem subsumir um ao outro. Nesse sentido, a experiência (Erfahrung) é entendida por Adorno como um processo dialético entre sujeito e realidade, socialmente mediada, baseada na tradição compartilhada, na transmissibilidade e na comunidade, e que tem como características ser uma relação refletida e preenchida com o vivido, ser uma possibilidade de percepção plena, cheia de sentido e que exige uma reflexão e uma imaginação ativa (Adorno, 1992; Benjamin, 1987). A experiência pressupõe comunicabilidade e compartilhamento entre os homens, isto é, o conteúdo produzido pela experiência pode ser compartilhado e compreendido por um grupo de indivíduos, fazendo sentido para eles.

Já a vivência (Erlebnis) é algo imediato, momentâneo, anterior às elaborações mentais que podem ser feitas quando se tem uma experiência (Amatuzzi, 2007). Erlebnis se refere a algo da ordem do privado, do individual, e como tal, não é compartilhável nem comunicável, não servindo para aproximar os homens, nem para significar suas ações. $\mathrm{Na}$ vivência, não há absorção do conteúdo, com uma real modificação do indivíduo, mas apenas o "choque", cada percepção é alheia às outras, meramente subjetiva que se esgota em si mesma, que não é realmente percebida, elaborada e integrada. Além disso, a vivência é eminentemente solitária, em comparação com a experiência, que, como já vimos, pressupõe um compartilhamento de significados, uma história e uma identidade coletiva (Adorno, 1992; Amatuzzi, 2007; Benjamin, 1987).

Se a vivência também apresenta seus aspectos positivos - para haver experiência, inicialmente é preciso ter havido vivência (Amatuzzi, 2007; Crochik, 2007), por outro lado, a característica da vivência é um contato passivo com a realidade, onde o fato é percebido e registrado, mas não é refletido.

Assim, a experiência pressupõe o pensamento livre e questionador, a capacidade para a reflexão e para a seriedade, a capacidade para lidar com o que não está pré-formado e, portanto, uma consciência da tensão, a capacidade para lidar com os extremos, com a contradição (Adorno, 1986d). A experiência não é compatível com o modo de vida nessa sociedade, com o ritmo exigido pela organização da produção e do consumo. Há um declínio das atividades coletivas (festas tradicionais, atividades coletivas e simbólicas), que ancoravam e significavam as experiências individuais. Assim, no lugar da experiência se coloca a busca desenfreada pelo novo, pela sensação, pelo "choque"- algo meramente subjetivo, sem relação com o objeto em si, um conhecimento fragmentado, estanque e isolado (Adorno, 1986, 1992). Por outro lado, tal sensação de novo é apenas aparência, visto que não há nada de novo nesse mundo administrado, tudo é falso, eterna repetição do mesmo com roupagem de novidade, um retorno compulsivo do antigo (Adorno, 1992; Crochik, 2007).

A aparência de que ainda existe um indivíduo autônomo, livre, de que há possibilidade de escolha, de que há racionalidade e necessidades objetivas, é necessária para manter a dominação e o próprio sistema como um todo. Considerando que a ideologia é a justificativa para a dominação e substitui a violência imediata; a própria realidade, como se apresenta como aparência, se tornou ideológica (Adorno, 1986c).

Nesse sentido, a sociedade é totalitária, pois os homens são obrigados a usar todas as energias de seu Ego para adaptar-se a ela, deixando de lado o seu próprio eu, a sua identidade. Dessa maneira, ele só alcança sua autoconservação à custa de uma regressão autoprescrita, de uma identidade com o todo falso (Adorno, 1986b, 1992). Nessa vida padronizada, o "mecanismo de identificação imediato do indivíduo com a instância social ... há muito já se apoderou dos modos de comportamento supostamente normais" (Adorno, 1992, p. 56).

É a esse processo, essa identidade com o todo falso, que Adorno vai nomear de coletivismo alienante. É uma sociedade que exige dos seus membros uma socialização radical, que "significa alienação radical" (Adorno \& Horkheimer, 1985, p. 66). Assim, esta não é uma sociedade individualista, no sentido de que não há mais indivíduos, mas é uma sociedade coletivista, que coage ao coletivismo, ao acabar com as diferenças qualitativas e ao reduzir tudo a uma igualdade para a dominação (Adorno, 1992). O discurso da liberdade do indivíduo é, na verdade, uma falsidade para encobrir o fato de que não há liberdade, que estão dados de antemão não só o papel que o indivíduo deve assumir na sociedade, mas as escolhas que ele pode fazer.

As pessoas pensam em bloco, a reflexão é substituída por reflexos pré-determinados. Na 
sociedade de produção em série, o próprio pensamento é produzido em série; questões complexas são naturalizadas e respondidas a partir de modelos conceituais e termos técnicos vazios, que independem do objeto (Adorno, 1992; Adorno \& Horkheimer, 1985). O pensamento, cada vez mais supérfluo, passa a ser considerado apenas mais um setor especializado da divisão do trabalho. Não há mais juízo, que necessita de discriminação e ponderação; mas uma simplificação, uma classificação em categorias, um mero reagir não reflexivo: "As etiquetas são coladas: ou se é amigo, ou inimigo" (Adorno \& Horkheimer, 1985, p. 188). Adorno chama de "mentalidade do ticket" esse pensar em bloco, em que a estereotipia substitui o trabalho categorial, e o indivíduo assume opiniões em bloco, em que "tomar posição", ter opinião sobre o que está acontecendo, na verdade, é uma escolha por alguns dos blocos de opinião socialmente sancionados; uma necessidade para se sentir socialmente incluído (Adorno, 1992; Adorno \& Horkheimer, 1985).

\section{$O$ caso estudado}

A luta pela terra é difícil e custosa para aqueles que buscam seus direitos. $\mathrm{O}$ assentamento estudado, situado em uma região conhecida por seus latifúndios e pela produção canavieira, se originou da aglutinação de vários acampamentos. Nesta pesquisa, tal assentamento foi acompanhado por cerca de um ano e meio, durante o período de transição de acampamento para assentamento. Realizaram-se entrevistas e observações participantes, as quais foram registradas em um diário de campo.

Várias das famílias que foram assentadas nessa comunidade viveram por aproximadamente oito anos em diferentes acampamentos. Durante o período de acampamento, foram constantes as mudanças, as ocupações, reintegrações de posse e reocupações, bem como as aglutinações de acampamentos diferentes.

Os assentados, quando vão narrar a luta pela terra, pontuam as dificuldades da luta, de estarem acampados em uma terra de usina, os despejos e reocupações, o medo de colocarem fogo nas barracas enquanto eles estivessem dormindo, o frio, a chuva, o montar e desmontar das barracas. Segundo Dona Ana, assentada ligada à liderança regional do MST, "agora que vão construir a casa dela, vai ser a $32^{a}$ moradia que ela construiu entre acampamento e assentamento" (Diário de campo, 20/10/06).

Já Geraldo, outro assentado militante, "teve muito medo de colocarem fogo no barraco, de um carro desgovernar e acertar eles lá" (Diário de Campo,
30/01/07). Havia também medo de apanhar da polícia ou de ser agredido por pessoas da cidade enquanto se estava dormindo: "Eu ficava com medo: e se a polícia vier aqui de noite e metê bala ni nóis?... esses barraco véio de lona, o cara passa aí na pista e dá um tiro aqui... vich!, eu tinha um medo danado."

Vários assentados verbalizam que a pior dificuldade encontrada foi a fome, pois dependiam da doação de alimentos, e nem sempre essas chegavam de forma suficiente. Na fala dos assentados, aparece, inclusive, o risco de inanição, em função de longos períodos que ficavam sem comer. Outra dificuldade muito grande foi a falta de água, seja para beber, seja para cuidar da higiene pessoal, visto que, como não havia água disponível, eles tinham que usar a água suja do rio:

O mais difícil, na época do acampamento, foi a questão da alimentação. ... chegou um momento que a gente tinha só fubá, fazê sopa de fubá pra se alimentar as familias, tinha que fazê na cozinha coletiva pra se dividir pra todo mundo ... Outra dificuldade muito grande, a questão da água, por devido à gente não ter apoio do município, então cê tinha que pegar água até suja no rio, que ela era água com esgoto, mas tinha que usar... então isso foi muito difícil pra nóis. (Sr. Angelo, entrevista)

Por outro lado, o que se pode perceber na fala dos assentados, com relação ao tempo de acampamento, é que este é visto como um momento significativo e de transformação de suas vidas. De uma forma geral, a participação no MST permitiu aos assentados uma experiência de participação diferenciada. Eles tinham um objetivo comum, racionalmente refletido e que era, de certa forma, a soma dos interesses individuais de cada um deles. Os assentados, em sua totalidade, relembram com saudosismo e com uma certa nostalgia da época de acampamento, e se referem ao tipo de relacionamento diferenciado que eles tinham então, colocando em evidência a solidariedade que havia entre eles.

A experiência de acampar e ocupar é muito significativa, constitui-se como um momento de ruptura. Caldart (2004) afirma que o momento simbólico de romper a cerca, de cortar o arame, é um momento a partir do qual o sujeito não é mais o mesmo, não pode mais voltar atrás. Mais do que romper a cerca, ao ocupar uma propriedade, o indivíduo rompe com uma posição passiva, que remete a uma aceitação da mesmice, da eterna repetição do já dado, e se permite um momento de crítica com relação à situação que lhe é apresentada como imutável, criando a possibilidade de tomarem em suas mãos a rédea de sua história, de fazerem seu próprio e diferente caminho: 
O que mudou em mim é sabê que é possivel ser dono do seu pensamento, falar com altivez, olhar pra cima e falar com qualquer pessoa de cabeça erguida. A cultura do Brasil tende a baixar a cabeça, as pessoas tendem a falar: 'sim senhor, sim senhor', baixar a cabeça. Dentro do Movimento, me deu a força de base... me deu a oportunidade de eu ser gente, ser humano pensante. (Sr. Vitor, entrevista)

Como podemos notar pelo exemplo acima, são claros os indícios de transformação de subjetividade nas pessoas que participaram da luta. Da fala do Sr. Vitor, transcrita acima, também podemos perceber que as pessoas saem de uma condição de seres humanos de segunda categoria, para os quais a posição nas relações assimétricas e de dominação era entendida como natural, como sendo de responsabilidade do próprio indivíduo que estava em posição de submissão, e passam a se ver como pessoas que têm valor, que são iguais aos outros, sendo que tal valorização se dá pela via do pensamento, da reflexão acerca da realidade.

Não é de menor importância o fato de experimentar isso de forma coletiva, ou seja, de terem tido uma oportunidade de reconstituírem-se como indivíduos, de reorganizar sua subjetividade, a partir de uma experiência coletiva. $O$ contato entre os indivíduos, proporcionado pela participação na luta pela terra, no grupo de pessoas acampadas, permite a identificação positiva com outros homens e mulheres, dando sentido e significado à experiência vivida, possibilitando a criação de vínculos libidinais entre os indivíduos, para além da tarefa imediata, que é a participação na luta pela terra (Adorno, 2006; Freud, 1996).

Os exemplos de produção de uma identidade coletiva, na presente pesquisa, apareceram de forma contundente. Os assentados verbalizaram, em várias oportunidades, que, na época de acampamento, eles se sentiam e se comportavam como sujeitos coletivos, pensando e agindo de forma coletiva:

Eu já apanhei, já apanhei várias vezes da polícia nessa luta que nóis tá. Já apanhei na Pontal, já apanhei ni outros assentamentos, mas nem por isso eu desisti, que se fosse por mim, eu desistia, mas eu sabia que através de mim, eu era um número nessa luta nossa, ela é feita por número, de cada um, de um até o dez. Eu não disse pra você que a gente era... que a gente teve um acampamento com mil e setecentas famílias, mais de cinco mil pessoas? Lá nóis era mais de cinco mil pessoas! (Sr. Arthur, entrevista)

A participação na luta pela terra permitiu ao indivíduo ter uma experiência de si próprio como indivíduo singular, ao mesmo tempo que criou um significado coletivo e transformador da própria subjetividade. Lembrando Horkheimer e Adorno
(1973, p. 71), “a proximidade estreita com outros homens e, por conseguinte, a afiliação em grupos que possibilitam o contato humano imediato, é uma condição óbvia do sentido de humanidade, de um modo geral". Nesse sentido, a participação em um acampamento do MST permitiu vivenciar a verdadeira igualdade, em contraposição ao igualitarismo repressivo imposto pela sociedade capitalista.

Houve a criação de um conteúdo coletivo, refletido e compartilhado, de uma significação coletiva da ação, ancorada em uma história comum. Na fala dos assentados, essa história tem relação com a história de outras gerações, seja de "lutadores do povo", seja de seus próprios antepassados familiares, não estando somente limitada ao período da luta. De acordo com alguns assentados, eles passavam a pensar de forma coletiva, indo de um raciocínio fechado em si mesmo para um outro que contempla os demais:

Num primeiro momento, você luta pela conquista da terra, pra readquirir a cidadania, você luta pela reforma agrária, e aí você vai adquirindo mais conhecimentos, ai você luta por uma transformação social, de um outro país, de um novo mundo que seja mais adequado pra todas as classes, um mundo melhor. Então o indivíduo não começa mais a pensar só nele, igual é lá na cidade, que você tem que ser melhor que todos, é só a sua sobrevivência, nessa caminhada depois você pensa de forma coletiva, no bem-estar de todos. Então é isso que muda na vida da gente. (Sr. Marco, entrevista)

Participar do momento de luta no acampamento também possibilitou ao assentado confrontar-se com o diferente, levando-o à reflexão sobre sua forma de vida, sobre concepções, ideias e preconceitos que foram internalizadas como naturais e que, se não são superados, passam pelo menos a ser problematizados, fazendo com que o sujeito passe a se questionar. Assim, a luta representa uma ruptura com o sempre igual da cidade, com o já dado, bem como uma oportunidade de quebra da igualdade opressiva do modo de vida em nossa sociedade, da mesmice que cada indivíduo acaba por repetir no meio urbano-industrial:

Cê cai aqui pro mato, pra roça, aí você tem que mudar muito os hábitos que tem na cidade, porque cê acaba entrando numa nova sociedade, entendeu? ... até a forma de conversar, a forma de trocar ideia com um companheiro, com outro, era muito diferente. As ideias não eram as mesmas, de jeito nenhum. $\mathrm{Na}$ cidade você tem um jeito de conversar, um jeito de falar, e quase todo mundo faz do mesmo jeito, e aqui você nota uma grande diferença, porque aqui você mistura com tudo... com tudo tipo de raça, cor, entendeu, então não tem... porque na cidade, querendo ou não, tem assim um certo tipo de preconceito... é... fulano é fulano, cicrano é cicrano, não se mistura, 
e quando se encontra no... nesse ambiente, que é uma nova sociedade... assim, do nosso Movimento... então, não tem aquela coisa de gênero, não se faz tanta questão de gênero, as tarefas são divididas praticamente de formas iguais, o homem pode lavar roupa, a mulher pode capinar e assim vai, assim vai a coisa, entendeu? Não tem aquela coisa de lésbica, gay, então são tratados todos como seres humanos. (Sr. Ivan, entrevista)

Do que vimos até o presente momento, podemos concluir que a participação no MST, na luta pela terra em seu período de acampamento, proporciona aos indivíduos uma possibilidade de rompimento do seu cotidiano reificado, permitindo que eles tenham uma experiência (Erfahrung) no sentido adorniano. A participação na luta estimula o pensamento livre e questionador, a capacidade para a reflexão, o desenvolvimento de uma autocrítica, a consciência de que a atual configuração não é algo acabado e imutável.

$\mathrm{O}$ que antes era naturalizado é questionado através do pensamento esclarecido, e a adaptação a um mundo de dominação é rompida, bem como a naturalização da consciência heterônoma e o processo de repetição do "sempre-o-mesmo", que visava adaptar o indivíduo, sem questionamentos, ao todo social que o oprimia.

A participação em um acampamento, que fortalecia o contato direto entre os indivíduos, possibilitou a criação de uma história e de significados compartilhados, o que acarretou no rompimento da alienação que separava os homens, que impedia que estes se reconhecessem como seres humanos. Tal construção de um sentimento de coletividade está fortemente ligada à possibilidade de experiência, que é ancorada num conteúdo coletivo e compartilhado.

Considerando que no mundo administrado, até mesmo a forma como as pessoas percebem as coisas é controlada, onde as pessoas têm somente vivências (Erlebnis), ou seja, apreendem o mundo e o que lhes acontece de forma não refletida, fragmentária e momentânea, sem integrar na consciência as percepções que lhe chegam de forma descontínua, individual e solitária, e na forma de clichês prontos para serem consumidos, a possibilidade de ter uma experiência, com as modificações que isto causa no indivíduo, é revolucionária.

Como a experiência se caracteriza pela integração das percepções no ego, com a consequente mudança no mundo interno do indivíduo, a participação no MST permite, ainda que momentaneamente, romper com a fragmentação do sujeito, bem como com a alienação do indivíduo de si próprio. Desse modo, a participação no
Movimento oportuniza ao indivíduo trilhar o caminho no sentido de sua autonomia, de sua emancipação.

Conforme os assentados, a união era maior no tempo de acampado, e foi diminuindo depois que passaram a ser assentados. Com isso, há um sentimento de que se perdeu alguma coisa ao se mudar de acampamento para assentamento:

Na época do acampamento, era muito mais coletivo que agora. Porque até por necessidade obriga a ser coletivo. Então, é uma questão de sobrevivência, mesmo. Mas se nóis tivesse continuado naquele mesmo esquema, de coletivo daquela época, hoje nóis taria muito melhor, o assentamento estaria mais avançado. (Sr. Ivan, entrevista)

Com a efetivação do assentamento e com o passar do tempo, há um declínio paulatino das atividades coletivas e simbólicas. Quase não ocorrem mais "místicas", os coletivos passam a se fragmentar, como também os espaços de discussão passam a se enfraquecer, e os indivíduos tendem a se isolar. Tanto os assentados quanto as lideranças do movimento social percebem esse processo, interpretando-o de formas diferentes e por vezes até antagônicas e, na quase totalidade das vezes, colocando a culpa de tal processo nos indivíduos.

$\mathrm{Na}$ fala da liderança, aparece com frequência a questão da falta de consciência dos demais assentados para se explicar a origem dos problemas ou desentendimentos, bem como a falta de união entre eles. Em reunião, discutindo as críticas feitas por alguns assentados às lideranças que não cuidavam de seus lotes e pouco ficavam no assentamento:

Rodrigo [liderança do MST] pediu a palavra e disse que

o problema preocupava porque talvez fosse um problema de compreensão politica, de compreender que eles saíam 'para fora' para fazer um trabalho importante, que permitiu que saisse um assentamento como aquele, ... e eles estão trabalhando para ter mais. ... 'A gente precisa ter entendimento político, união’. (Diário de campo, 11/01/2007)

$\mathrm{Na}$ fala dos técnicos estatais, que passam a ter uma inserção diferente no assentamento, aparece a questão do dinheiro como motivação para o surgimento das dificuldades.

Helena [técnica do INCRA] disse que os assentados não conseguem se organizar mais, que foi só sair o dinheiro que começou a 'brigaiada', que compraram por conta própria, ao contrário da recomendação técnica, tratores e implementos desnecessários, que para o assentamento todo, um trator dava, e ainda 
ia ficar sem uso em uns dois anos. (Diário de campo, 27/06/2007)

Já os assentados se defendem da acusação de não terem consciência, e reportam a uma postura autoritária por parte do MST e da assistência técnica na relação com eles, tentando impor uma forma de trabalho ou de organização. Assim se coloca o Sr. Arthur, assentado, em uma reunião da Coordenação Geral: "Temos que sair deles, é uma ditadura, nóis não vamo deixar pôr algema em nóis ... primeiro é a coordenação (MST), agora é eles (INCRA) querendo mandar na gente" (Diário de campo, 09/05/2007).

Além disso, também aparece a questão do dinheiro no discurso dos assentados, seja corroborando a posição apresentada pelos técnicos do Poder Público, de que, quando o dinheiro entra, os assentados já não querem saber mais de mobilização, seja acusando a direção do MST de ter o mesmo comportamento, isto é, de ter se afastado da base em função de estar tendo uma vida tranquila financeiramente. Sobre o comportamento da base a partir do momento em que saíram os recursos, assim se manifesta um assentado:

\begin{abstract}
A partir do momento que entra dinheiro... o dinheiro muda a vida das pessoas, então as pessoas começam a se sentir, como se diz, dona do nariz, já não acha mais que... que aquela discussão coletiva, que aquela... aquela mística coletiva que tinha, porque todas reunião tinha uma mística, então a coisa era mais movimentada pela mística da vida, entendeu, a partir do momento que pegaram recursos, fomento, PRONAF, a pessoa acabaram muitos pensando de forma diferente, aonde, que eu digo, que as coisas poderiam estar bem melhor [se tivessem continuado trabalhando de forma coletiva]. (Sr. Ivan, entrevista)
\end{abstract}

Com a transformação do acampamento em assentamento, os assentados dividiram-se em núcleos, cada um mudou-se para o seu lote, e passaram a se ver com questões do dia a dia, como a construção das casas, a organização/ reorganização das famílias, o início da produção, a necessidade da comercialização. Quando o indivíduo é finalmente assentado, após anos de luta, na maioria das vezes, está completamente descapitalizado, pois, como vimos, ele mal tinha recursos para se alimentar na época de acampamento.

Paralelamente a isso, há a entrada de novos atores no espaço do assentamento, como os técnicos do Estado, que imporão exigências para o enquadramento dos assentados no acesso a seus programas de apoio e recursos financeiros. Soma-se a isso a pressão para produzir, para mostrar para a sociedade que o assentamento "dá certo".
A máxima de que "tempo é dinheiro", adequada à forma de organização do tempo dos indivíduos no sistema capitalista, em que até o ócio é instrumentalizado e organizado segundo os interesses de produção e de lucro, através dos mecanismos da indústria cultural, também passa a influir na distribuição e na organização do tempo do assentado, com a entrada da lógica da mercadoria no assentamento. A lenta e crescente adaptação ao sistema capitalista contribui para o esvaziamento dos espaços públicos, justamente em função de o tempo dos assentados passar a ser medido segundo o princípio do equivalente.

Nesse sentido, participar de reuniões, de discussões, é "perda de tempo", ou seja, dispêndio de um tempo que poderia estar sendo investido na produção de mercadorias agrícolas e na comercialização dessas mercadorias. Da mesma forma, assumir o papel de coordenador de núcleo ou do assentamento implica em dispor de seu tempo de produtor rural para uma atividade cujo retorno não pode ser objetivamente medido, pelo menos não de forma imediata. Com isso, os espaços públicos de discussão e de construção coletiva ficam esvaziados, com sérios riscos de deixarem de existir.

Assim, com a entrada da lógica da mercadoria no assentamento, há uma desmobilização dos assentados, bem como um esmorecimento em sua contraposição esclarecida ao sistema capitalista. A fragmentação daí decorrente é escamoteada e entendida como algo negativo, tanto para assentados, quanto para o movimento social e para os agentes estatais que atuam em tal espaço.

Outro ponto a ser observado é a presença, dentro do movimento social, de duas lógicas contraditórias que subsistem de forma perene e estrutural: a lógica do acampamento, que é a lógica da reflexão, do questionamento, da luta; e a lógica do assentamento, que inevitavelmente envolve as questões da produção, reprodução e de sobrevivência dentro da sociedade capitalista, com uma inserção inevitável dentro desta.

Caldart (2004) narra um momento interessante e pouco citado na constituição do MST, quando são criados os primeiros assentamentos, nos anos oitenta. Nessa ocasião, discutiu-se a possibilidade de criação de um novo movimento social (o "Movimento Pé No Chão") - opção esta posteriormente descartada, uma vez que se decidiu que o MST seria também a organização representante das famílias assentadas. O objetivo então aventado para o "Movimento Pé No Chão" seria o de organizar e lutar pelos interesses específicos dos assentados, já que suas questões específicas dizem respeito a como manter-se assentado dentro de um sistema que tende a expulsá-lo novamente 
para a cidade, e envolve problemas como obtenção de crédito, facilitar a comercialização, evitar a pauperização, permitir a capitalização dos indivíduos, entre outros.

Caldart (2004, p. 137) vai, inclusive, nomear os assentados de "dirigentes de empresa", que atuariam conforme uma lógica da pequena "empresa social". $\mathrm{Na}$ verdade, coexistiriam, de forma tensa e dialética, dentro do próprio MST, as duas lógicas: a lógica do "rolo" (ou "do movimento") e a da "empresa social" ("da organização, do planejamento"), as quais, na opinião da autora, foram decisivas para constituir a atual formação da estrutura do próprio Movimento, que por vezes atua com "uma pitada" da lógica da empresa social.

Essa lógica, encampada pelo Movimento, acaba por submeter o indivíduo e seu funcionamento subjetivo ao princípio do equivalente. A primazia dos aspectos econômicos e produtivos leva o Movimento a se deparar com questões "éticas" típicas do sistema capitalista, como: produzir para todos ou dirigirse a nichos de mercado, que pagam melhor, mas atingem somente a elite; como se relacionar com outros pequenos produtores rurais não assentados, em especial quanto à questão do lucro, tendo-se em vista que muitas vezes se negocia com os referidos produtores; como comprar ou vender a indivíduos ou empresas que muitas vezes se colocam de forma contrária à reforma agrária, mas cujo relacionamento comercial permitirá capitalizar grandemente aquele assentamento ou aquela cooperativa (Caldart, 2004).

Pontuamos ainda que não é de menor importância a mudança do papel do Estado na relação com os assentados e com a liderança do MST, mudança esta que contribui com a entrada do princípio do equivalente no assentamento e para aprofundar as divergências que começam a se evidenciar na relação entre assentados e movimento social, mas esse ponto, por si só, daria um estudo à parte.

De todas as formas, o que não se pode esquecer é que ambos (assentamento e movimento social) são espaços em disputa e, como todo espaço social, sujeitos a contradições. Romantizar o assentamento e mascarar as contradições que são inevitáveis, ou mesmo reportar tais contradições aos indivíduos (sejam eles os assentados, a liderança, ou mesmo os técnicos estatais), somente contribui para que essa relação com o todo social, da qual ainda não se pode escapar, seja velada e mistificada, contribuindo com a reificação e alienação do indivíduo, e com a dissolução da força contestadora do movimento social. Essa postura também engessa o movimento dialético, porque nega a contradição, contribuindo para que não possa ser superada, bem como veicula a ideia de que a síntese esperada para o futuro já aconteceu.

Há que se assinalar que a idealização do assentamento não contribui para o avanço da luta, mas somente para mascarar a realidade e induzir a uma falsa compreensão dos processos sociais e individuais que ocorrem na fase pós-assentamento, o que somente acentua a cisão e os desentendimentos, dificultando qualquer possibilidade de construção de um trabalho conjunto, que possa efetivamente colaborar com a emancipação dos indivíduos.

Por último, gostaríamos de frisar o potencial emancipador presente no MST. Se, como pontua Sigaud (2005), ao entrar no movimento social, o indivíduo não está pensando em modificar a sociedade, mas optando por uma estratégia de sobrevivência entre as possíveis para ele (subemprego na cidade, trabalho volante nas fazendas, bolsa-família), cabe destacar que o indivíduo que emerge após a participação no Movimento é diferente do que emerge do recebimento de benefícios sociais ou do trabalho alienado. No caso da participação no MST, os indivíduos se identificavam uns com os outros, tinham um contato real com o outro, ao mesmo tempo que reorganizavam sua subjetividade em função da experiência que pôde ter ao participar do movimento social. Com seu pertencimento ao Movimento, o indivíduo experimentou a emergência de uma consciência autônoma, da mesma maneira que construiu uma história coletiva, cujo conteúdo e significação eram partilhados pelos outros participantes da luta (Figueiredo, 2009). Participar do MST permitiu, assim, um verdadeiro encontro com outros seres humanos, por meio de relações solidárias e não submetidas ao princípio do equivalente.

Dessa forma, pode-se perceber que há realmente uma transformação na vida daqueles que participam do movimento social, e isso não tem somente relação com o fato de eles passarem a ter uma vida mais digna. Há uma mudança nas pessoas, que tiveram uma experiência (Efahrung) ao entrarem para o MST, e depois disso, mesmo que "recuem na consciência", nunca mais voltarão a ser as mesmas. O Movimento proporcionou a tais pessoas terem uma identificação coletiva, uma relação com o todo não reificada e reflexiva, o que gerou impactos na subjetividade. Contudo, embora a enorme força do referido processo, a ameaça de incorporação à lógica do mercado com a qual convivem tanto assentados quanto o movimento social coloca em constante tensão e risco essa nova possibilidade. 


\section{Nota}

1 Movimento é o termo utilizado por alguns autores para se referir ao Movimento dos Trabalhadores Rurais Sem Terra - o MST. Neste trabalho, utilizaremos tanto MST quanto Movimento.

\section{Referências}

Adorno, T. W. (1986). Educação pós-Auschwitz. In G. Cohn (Org.), Theodor Adorno (pp. 33-45). São Paulo: Ática.

Adorno, T. W. (1986b). Acerca de la relación entre sociología e psicología. In H. Jensen (Org.), Teoria critica del sujeto (pp.36-83). Buenos Aires: Ed. Siglo XXI.

Adorno, T. W. (1986c). Crítica cultural e sociedade. In G. Cohn (Org.), Theodor Adorno (pp. 76-91). São Paulo: Ática.

Adorno, T. W. (1986d). Por que é difícil a nova música. In G. Cohn (Org.), Theodor Adorno (pp. 147- 161). São Paulo: Ática.

Adorno, T. W. (1992). Minima moralia: reflexões a partir da vida danificada. São Paulo: Ática.

Adorno, T. W. (2006). Teoria Freudiana e o padrão da propaganda fascista. Margem Esquerda, 7, 159-189.

Adorno, T. W. \& Horkheimer, M. (1985). Dialética do esclarecimento: fragmentos filosóficos. Rio de Janeiro: Jorge Zahar Editores.

Amatuzzi, M. (2007). Experiência: um termo chave para a psicologia. Memorandum, 13, 08-15. Acesso em 10 de outubro, 2008, em www.fafich.ufmg.br/ memorandum/a13/ amatuzzi05.pdf

Associação Nacional de Cooperação Agrícola - ANCA. (2002). O que levar em conta para a organização do assentamento: a discussão no acampamento. São Paulo: Autor.

Benjamin. W. (1987). Experiência e pobreza. In W. Benjamin, Obras escolhidas. Magia e técnica, arte e política (pp. 114119). São Paulo: Brasiliense.

Caldart, R. S. (2004). Pedagogia do Movimento Sem Terra. São Paulo: Expressão Popular.

Caume, D. J. (2002). A tessitura do "assentamento de reforma agrária": discursos e práticas instituintes de um espaço agenciado pelo poder. Tese de doutorado, Programa de Pós-graduação em Sociologia, Universidade Estadual de Campinas, Campinas, SP.

Confederação Nacional das Cooperativas de Reforma Agrária do Brasil - CONCRAB. (2004). Novas formas de assentamentos de reforma agrária: a experiência da Comuna da Terra. Brasília, DF: CONCRAB/INCRA/CRT.

Crochik, J. L. (2007). Teoria Crítica e formação do indivíduo. São Paulo: Casa do Psicólogo.

D’Incao, M. C. \& Roy, G. (1995). Nós, cidadãos: aprendendo e ensinando a democracia. Rio de Janeiro: Editora Paz e Terra.

Figueiredo, G. C. (2009). Experiência e luta pela terra: o assentamento Sepé Tiaraju e o MST. Tese de doutorado, Programa de Pós-graduação em Psicologia, Universidade de São Paulo, Ribeirão Preto, SP.

Freud, S. (1996). Psicologia de grupo e análise do ego. Rio de Janeiro: Imago.

Horkheimer, M. \& Adorno, T. W. (1973). Temas básicos de sociologia. São Paulo: Cultrix/Edusp.

Leite, S. (1997). Assentamentos rurais no Brasil: impactos, dimensões e significados. In J. P. Stédile (Org.), A reforma agrária e a luta do MST (pp. 157-176). Petrópolis, RJ: Vozes.
Medeiros, L. S. (2003). Reforma Agrária no Brasil: história e atualidade da luta pela terra. São Paulo: Fundação Perseu Abramo.

Miranda, M. E. (1998). Análise de uma situação de conflito entre os assentados e o MST. Dissertação de Mestrado, Programa de Pós-graduação em Sociologia, Universidade de São Paulo, São Paulo, SP.

Schreiner, D. F. (2002). Entre a exclusão e a utopia: um estudo sobre os processos de organização da vida cotidiana nos assentamentos rurais. Tese de Doutorado, Programa de Pósgraduação em Sociologia, Universidade de São Paulo, São Paulo, SP.

Sigaud, L. (2005). As condições de possibilidades de ocupação de terra. Tempo Social: Revista de Sociologia da USP, 17(1), 255-280.

Spavorek, G. (2003). A qualidade dos assentamentos da reforma agrária brasileira. São Paulo: Páginas e Letras.

Stédile, J. P. (1997). A reforma agrária e a luta do MST. Petrópolis, RJ: Vozes.

Turatti, M. C. M. (2005). Os filhos da lona preta. São Paulo: Editora Alameda.

Vasquez, A. P. (2001). Agricultores, companheiros, irmãos: estudo sobre cultura e religião entre os assentados de Sumaré I. Dissertação de Mestrado, Programa de Pós-graduação em Sociologia, Universidade de São Paulo, São Paulo, SP.

Submissão em: 20/05/2012

Revisão em: 29/06/2012

Aceite em: 18/08/2012

Gislayne Cristina Figueiredo é graduada em Psicologia pela Universidade de São Paulo (1998), mestrado (2001) e doutorado (2009) em Psicologia pela Universidade de São Paulo - FFCLRP. Professora titular do curso de Psicologia da Universidade Paulista. Experiência técnica na área de

Psicologia, atuando principalmente nos seguintes temas:

psicologia social, políticas públicas, exclusão social e assentamentos rurais. Endereço: R. Adalberto Panzan, 300, casa 8. Sorocaba/SP. CEP 18085-844 E-mail: gislaynecf@hotmail.com

José Marcelino de Rezende Pinto é licenciado em Física (1982) e bacharel em Direito (1985) pela Universidade de São Paulo, com mestrado em Educação (1989) e doutorado em Educação (1994) pela Universidade Estadual de Campinas. Atualmente é professor associado da

Universidade de São Paulo. Tem experiência na área de

Educação, com ênfase em Financiamento da Educação, atuando principalmente nos seguintes temas: financiamento da educação, municipalização do ensino, finanças públicas, cidadania e educação do campo. E-mail: jmrpinto@ffclrp.usp.br

\section{Como citar:}

Figueiredo, G. C. \& Pinto, J. M. R. (2014). Acampamento e assentamento: participação, experiência e vivência em dois momentos da luta pela terra Psicologia \& Sociedade, 26(3), 562-571. 